\title{
Judicialização da saúde: uma revisão sistemática de literatura das iniciativas de diálogo institucional intersetorial
}

Health judicialization: a systematic review of literature about initiatives of institutional intersectorial dialogue

Judicialización de la salud: una revisión sistemática de la literatura sobre las iniciativas del diálogo institucional intersectorial

Elisângela César dos Santos Anjos ${ }^{1}$

Danilo da Costa Ribeiro ${ }^{2}$

Leonnardo Vieira Morais ${ }^{3}$

\section{Resumo}

Objetivo: levantar as iniciativas de diálogo institucional intersetorial no escopo da judicialização da saúde, estabelecidas desde a criação do Fórum da Saúde pelo Conselho Nacional de Justiça, em 2010. Metodologia: foi realizada uma revisão sistemática de literatura por meio da aplicação dos critérios do Preferred Reporting Items for Systematic Reviews and Meta-Analyses (PRISMA) entre 2010 e 2018. Resultados: foram selecionados sete artigos científicos que apontaram para a existência de diversas iniciativas exitosas no diálogo institucional e intersetorial, repercutindo de forma relevante sobre a redução das ações judiciais em saúde e sobre a mitigação da judicialização da saúde. Conclusão: depreende-se que o fenômeno da judicialização da saúde, por sua complexidade e pela multiplicidade de atores e interesses circunscritos a ele, pode ser manejado e mitigado por vias que favoreçam a interdisciplinaridade entre Direito e Saúde.

\section{Palavras-chave}

Direito à saúde. Judicialização da saúde. Poder Judiciário. Colaboração intersetorial.

\begin{abstract}
Objective: this study aimed to raise the initiatives of intersectorial institutional dialogue within the scope of the judicialization of health established since the creation of the Forum of Health by the National Council of Justice in 2010. Method: a systematic review of literature was conducted through the application of the criteria of the Preferred Reporting Items for Systematic Reviews and Meta-Analyses (PRISMA). Results: seven scientific articles selected pointed to the existence of several successful initiatives in the institutional and intersectorial dialogue, with a relevant repercussion on the reduction of health judicial actions and on the mitigation of health judicialization. Conclusion: it is understood that the phenomenon of health judicialization, due to its complexity and the multiplicity of actors and interests circumscribed to it, can be managed, and mitigated by ways that favor the interdisciplinarity between Law and Health.
\end{abstract}

\footnotetext{
${ }^{1}$ Doutoranda em Governança Digital, Universidade Federal de Tocantins, Palmas, Tocantins, Brasil; analista técnica de políticas sociais (ATPS), Ministério da Saúde. https://orcid.org/0000-0003-3242-3609. E-mail: elisangela.anjos@saude.gov.br ${ }_{2}^{2}$ Mestre em Direitos Humanos; docente, Faculdade de Direito, Centro Universitário ICESP, Brasília, Distrito Federal, Brasil. https://orcid.org/0000-0003-3929-9321. E-mail: dcr.adv@gmail.com

${ }^{3}$ Especialista em marketing; docente, Faculdade de Direito, Centro Universitário ICESP Brasília, Distrito Federal, Brasil. https://orcid.org/0000-0003-0359-1726. E-mail: leonnardo.morais@icesp.edu.br
} 


\section{Keywords}

Right to health. Judicialization of health. Judicial power. Intersectorial collaboration.

\section{Resumen}

Objetivo: elevar las iniciativas de diálogo institucional intersectorial dentro del alcance de la judicialización de la salud establecida desde la creación del Foro de Salud por el Consejo Nacional de Justicia en 2010. Metodología: se realizó una revisión sistemática de literatura a través de la aplicación de los criterios de los Elementos de Informes Preferidos para Revisiones Sistemáticas y Metaanálisis. Resultados: se seleccionaron siete artículos científicos que señalaron la existencia de varias iniciativas exitosas en el diálogo institucional e intersectorial, con una repercusión relevante en la reducción de las acciones judiciales de salud y en la mitigación de la judicialización de la salud. Conclusión: se entiende que el fenómeno de la judicialización de la salud, debido a su complejidad y la multiplicidad de actores e intereses circunscritos a él, puede ser manejado y mitigado de maneras que favorezcan la interdisciplinariedad entre la Ley y la Salud.

\section{Palabras clave}

Derecho a la salud. Judicialización de la salud. Poder Judicial. Colaboración intersectorial.

\section{Introdução}

A saúde está positivada no artigo 196 da Constituição Federal de 1988 como "direito de todos e dever do Estado, garantido mediante políticas sociais e econômicas (...)" (1). Não se constitui um desafio modesto: a Carta Magna promete amparar ampla e irrestritamente todo aquele que estiver em solo brasileiro, ainda que tenha o quinto maior contingente populacional mundial. Seria de se esperar, portanto, que um sistema de tal porte e com a missão de assistência de saúde integral a mais de 200 milhões de usuários apresentasse dificuldades e limitações típicas de um setor saúde cuja essência prestacional jamais se esgotará, tampouco superará em ofertas a toda a sua demanda.

Há questões dificultosas no Sistema Único de Saúde (SUS) e que frequentemente ocupam mídias e redes sociais. É nesse ambiente social de inconformidade com a fruição do direito individual à saúde que um número exponencialmente crescente de usuários tem recorrido ao Poder Judiciário para requerer a eficácia devida por parte do SUS, principal estratégia estatal do setor saúde, pertencente essencialmente às esferas do Poder Executivo e Poder Legislativo.

A tal fenômeno chama-se judicialização das políticas de saúde ou judicialização da saúde, de característica multifacetada e institucionalmente conflituosa, por envolver o setor da saúde, o sistema de justiça, os Poderes republicanos, e instituições e órgãos que tratam da temática (2-4). 
De um lado, o setor saúde se ressente de que os juízes, desprovidos de qualquer conhecimento técnico em saúde que seria absolutamente imprescindível para resolução escorreita da ação que estão a apreciar, tendem a aprovar irrestritamente toda e qualquer tecnologia de saúde que é demandada. Os magistrados desconhecem que o insumo demandado, em geral, não possui registro na Agência Nacional de Vigilância Sanitária (Anvisa) exatamente por não ter sido testado quanto aos requisitos mínimos de segurança clínica para uso populacional ou, ainda, quanto à garantia de seus resultados terapêticos (5). Além disso, em diversos casos, o SUS já provê, de ofício, diversos tratamentos com eficácia e segurança clínica idênticos ou superiores ao insumo demandado (6). Tal sentença traz desorganização à gestão do sistema de saúde, por representar um gasto exorbitante e não planejado, o que compromete a garantia e a sustentabilidade do direito coletivo em detrimento do direito individual judicializado $(7,8)$.

De outro lado, o sistema de justiça pondera que, há a necessidade de romper com a inércia dos demais poderes para salvaguardar o direito subjetivo pleiteado, o qual pode não estar em franco risco ao ponto de se lançar mão do caminho judicial para resolução do pleito de forma recorrente, e não mais de forma excepcional (9-11).

Em 2009, o Supremo Tribunal Federal (STF) realizou a Audiência Pública $\mathrm{n}^{\circ} 4$, também conhecida como a Audiência Pública da Saúde (APS), para propiciar a discussão de representantes dos diversos segmentos que compõem essa arena: gestores públicos de todas as esferas federadas do SUS, profissionais de saúde com expertise no assunto, Defensoria Pública, Procuradoria, Ministério Público, Magistrados, setor industrial (notadamente segmento farmacêutico) e sociedade civil organizada na figura de associações de pacientes e usuários (12-14)

Após a APS, ficou clara a necessidade de construção de espaços que integrassem esforços do direito e da saúde a fim de mitigar o fenômeno da judicialização. Em resposta, em 2010, o Conselho Nacional de Justiça (CNJ) cria a Recomendação n 31, de 30/3/2010 (15) - orientando os Tribunais à adoção de medidas que melhor subsidiem os magistrados e demais operadores do direito nas demandas judiciais que envolvem a questão saúde - e publica a Resolução $n^{\circ}$ 107, de 6/4/2010 (16), que institui o Fórum Nacional do Judiciário para monitoramento e resolução das demandas judiciais de assistência à saúde, também denominado Fórum da Saúde (17).

Ambas as iniciativas buscam fomentar o diálogo e articulação intersetorial entre o sistema do direito e o sistema de saúde, como que vislumbrando nessa via negocial o melhor 
caminho para dar respostas às ações de saúde e para deter o avanço da judicialização. desafio que se apresentava não era somente o de promover a aproximação entre os sistemas de saúde e de justiça, mas principalmente mitigar a judicialização da saúde como alternativa exorbitante e potencialmente prejudicial às instituições, poderes e sistemas envolvidos $(13,14)$.

Entende-se a relevância do delineamento dessas questões em razão da própria fundamentalidade do direito à saúde e do risco que o fenômeno da judicialização extremada desse direito pode representar à sustentabilidade do sistema público de saúde. Considerase, por hipótese, que jazem nas iniciativas de diálogo institucional e intersetorial as melhores possibilidades de contenção da marcha expansiva do fenômeno da judicialização da saúde.

Transcorrida uma década desde o chamamento reflexivo e colaborativo entre direito e saúde simbolizado na APS e, por consequência desta, nas normativas produzidas pelo CNJ em favor de tal alinhamento institucional sobre a matéria, é que se buscou, por meio deste estudo, identificar quais foram as iniciativas de diálogo institucional intersetorial no escopo da judicialização da saúde estabelecidas desde a criação do Fórum da Saúde pelo CNJ em 2010.

\section{Metodologia}

Quanto à caracterização do estudo, optou-se por uma revisão sistemática de literatura (RSL) para identificação das iniciativas de diálogo institucional intersetorial no escopo da judicialização da saúde estabelecidas desde a criação do Fórum da Saúde pelo CNJ em 2010.

Uma RSL é precisamente o desenho de estudo que se presta à tentativa tanto de compilação das evidências dispersas nas melhores publicações sobre uma temática comum como de esclarecimento das disparidades que envolvem a questão. É um produto de abrangência e profundidade, que busca trazer uma contribuição original e organizadora dos saberes disponíveis em determinado tema de forma não tendenciosa (18).

O recorte temporal escolhido teve como referência, a Resolução $n^{\circ} 107$, de 6/4/2010, que instituiu o Fórum da Saúde (16) e que representa o ponto inaugural institucional quanto às abordagens dialogadas e à articulação intersetorial na temática da judicialização da saúde.

Na RSL, foram aplicados os critérios do Preferred Reporting Items for Systematic Reviews and Meta-Analyses (PRISMA) (19), sendo ajustados aqueles que não foram 
aplicáveis à natureza descritiva do estudo. Sinteticamente, o trajeto metodológico percorreu o cumprimento de seis etapas: formulação do problema; pesquisa na literatura e seleção dos estudos com base nos critérios de elegibilidade e exclusão; avaliação da qualidade dos estudos selecionados; análise de dados; interpretação de resultados; e apresentação da discussão e conclusões.

Trata-se, portanto, de um trabalho exploratório-descritivo, com abordagem qualitativa, a partir dos estudos selecionados pela RSL por meio da aplicação de critérios orientados pelo protocolo PRISMA.

Foram incluídos estudos que: (a) constituíssem artigos científicos; (b) redigidos em português, inglês e espanhol; (c) disponíveis em seu inteiro teor de forma gratuita no momento da busca nas bases eletrônicas de dados e interfaces consultadas (SciELO, LILACS, MEDLINE/PubMed e Embase), além do Portal Periódicos CAPES, Google Scholar e Biblioteca Virtual em Saúde (BiREME); (e) publicados entre 2010 e 2018; (f) fossem de periódicos classificados pelo Sistema Qualis Periódicos no quadriênio 2013-2016 como A1, $\mathrm{A} 2$, B1 e/ou B2 em pelo menos uma das áreas temáticas de saúde coletiva e direito; $(\mathrm{g})$ identificáveis por meio da busca combinada de descritores catalogados na Biblioteca Virtual em Saúde - DeCS/BVS (judicialização da saúde, decisões judiciais, Poder Judiciário, direito à saúde, Sistema Único de Saúde, colaboração intersetorial) e suas variantes em inglês e espanhol; (h) inicialmente, pela leitura do título e do resumo, tivesse conteúdo voltado às iniciativas de articulação institucional entre os sistema de saúde e o sistema de justiça no contexto da judicialização da saúde; ou (i) com conteúdo voltado à revisão de estudos detidos ao mesmo conteúdo e abordagem. As listas de referências apresentadas pelos estudos selecionados por esses critérios foram consultadas para identificação de outros artigos elegíveis por esses mesmos critérios.

Foram excluídos estudos que apresentavam: (a) estrutura diversa ao formato de artigo científico (anais de eventos científicos, monografias, dissertações, teses, boletins informativos, pôsteres, ensaios, editoriais, resenhas, trabalhos de conclusão de cursos); (b) duplicidades de título apontadas por bases de dados diferentes; (c) artigos oriundos de periódicos não cadastrados ou sem classificação em ambas as áreas temáticas de saúde coletiva e direito, ou com classificação B3, B4 e B5 em ambas as áreas temáticas de saúde coletiva e direito, ou, ainda, com classificação $\mathrm{C}$ em pelo menos uma das áreas temáticas de saúde coletiva e direito; (d) artigos cujo teor não tratasse das iniciativas de articulação institucional entre os sistemas de saúde e o sistema de justiça no contexto da judicialização 
da saúde pela leitura de inteiro teor do artigo, ou com conteúdo voltado à revisão de estudos detidos ao mesmo conteúdo e abordagem.

\section{Resultados}

Da aplicação dos critérios de inclusão e de exclusão apresentados, foi realizada uma pré-seleção de dezessete artigos científicos, dos quais dois foram excluídos por fuga ao tema após a leitura de inteiro teor e oito em razão da classificação Qualis Periódicos Capes em estratos B3, B4, B5 e C, conforme representado na Figura 1.

Figura 1. Fluxo de seleção dos estudos da RSL

72 estudos encontrados como resultados de busca nas bases de dados

17 estudos identificados como potencialmente elegíveis pelo título e pré-selecionados para leitura de resumos e inteiro teor

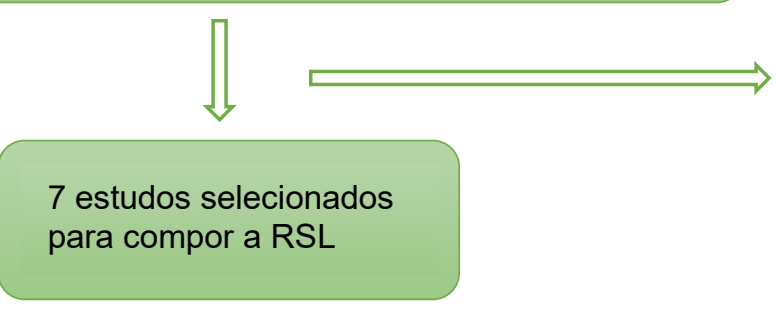

10 estudos excluídos, sendo 2 por fuga ao tema e 8 por classificação Qualis Capes abaixo de B2

Fonte: elaborada pelos autores.

Permaneceram, portanto, na amostra final deste estudo, sete artigos científicos selecionados, conforme sintetizado no Quadro 1, dispostos em sequência cronológica de publicação nos respectivos periódicos científicos, cada qual com o seu registro ISSN e sua classificação por área temática. 
Considerando o recorte temporal da pesquisa e a amostra selecionada, identifica-se que a temática tem sido pouco descrita por meio de estudos. A totalidade dos artigos aponta caminhos a serem trilhados prospectivamente, sugerindo que, embora haja diversos níveis de recomendações em prol do diálogo cooperativo entre Poder Judiciário e Poderes representativos, a concretização dessa articulação ainda se encontra em fase inicial.

Chama a atenção o achado aleatório e positivo de que três estudos da amostra estão vinculados a periódicos de melhor classificação na área de Saúde Coletiva e outros quatro estudos da amostra estão vinculados a periódicos melhor classificados na área do Direito, sendo que um dos estudos do último grupo foi elaborado de forma interdisciplinar, com autoria de profissionais da saúde e do direito. Tal fato garantiu equilíbrio ao debate entre as percepções extraídas dos autores, sem que houvesse predominância ou sobreposição de uma matriz de pensamento em detrimento da outra.

Somente um estudo (25) se debruçou inteiramente a compartilhar uma experiência exitosa de iniciativa de diálogo institucional intersetorial no escopo da judicialização da saúde. Tal vivência se deu a partir da criação do Núcleo de Conciliação de Medicamentos em Lages (SC) por inquietação do juiz local, o que se tornou um formato modelo e matriciador para todo o consórcio municipal existente na região, resultando no que os autores denominam de "mútua capacitação" (aprendizado compartilhado e bidirecional entre operadores do direito e gestores da saúde), superação da lógica competitiva e adversarial entre as áreas do direito e da saúde e ampliação dos espaços de diálogo e construção de consensos, repercutindo de forma relevante sobre a redução da litigiosidade na matéria da saúde e sobre a melhoria do sistema de saúde público local.

Houve um artigo (23) que citou duas experiências exitosas de articulação intersetorial: a) a Câmara Permanente Distrital de Mediação em Saúde, criada pela Defensoria Pública do Distrito Federal para trabalhar conflitos afetos à saúde entre usuários do SUS, gestores da saúde e operadores do direito; b) o Centro de Apoio Operacional das Promotorias de Justiça de Defesa da Saúde, um trabalho itinerante em Minas Gerais, que realiza visitas às regiões do estado para promover reuniões de conciliação entre usuários, gestores de saúde e operadores do direito.

Entretanto, os autores interpretaram que, apesar de a mediação de conflitos em espaços judiciais representar avanços no enfrentamento da judicialização da saúde, caberia prioritariamente ao sistema de saúde inaugurar espaços ligados institucionalmente às secretarias estaduais e municipais de saúde para promover o que os autores denominam 
"mediação sanitária", com monitoramento das ações relacionadas à saúde e sua consequente mitigação e prevenção. Os autores identificaram que a judicialização da saúde ameaça os princípios do SUS, sobretudo o da equidade, por não ter o poder de instituir de pronto a concessão do insumo deferido na ação judicial a todos os usuários que se encontram em igualdade de condições com o autor da ação.

Outro estudo (21) relatou que, desde a criação do Fórum da Saúde pelo CNJ, têm sido criados Núcleos de Assessoria Técnica (NATs) em vários estados para prover suporte técnico aos magistrados. Os núcleos possuem uma equipe multidisciplinar que indica, em parecer técnico, os aspectos clínicos sensíveis a serem considerados na ação e as políticas públicas existentes no setor da saúde que se relacionam ao fornecimento do insumo demandado na ação judicial em questão.

Além do sucesso dos NATs, os autores entenderam que surgiram outros ganhos importantes desde a criação do Fórum da Saúde, tais como: o aprimoramento regulatório sobre os insumos pelo Ministério da Saúde (MS) e pela Anvisa; a formulação de protocolos clínicos e diretrizes terapêuticas (PCDT), publicados pelo MS para atrelar a concessão de alguns insumos estratégicos mediante o cumprimento de critérios calcados em evidências científicas em saúde; além de recomendações do CNJ em favor do diálogo institucional intersetorial sobre a judicialização da saúde e em prol do uso dos PCDT como forma de mitigação de deferimentos que envolvam insumo não autorizado pela Anvisa e MS e como forma de prevenção de eventual interferência da indústria farmacêutica. Os autores perceberam que o controle da judicialização da saúde é uma urgência, pois sua progressão coloca em risco a equidade do sistema de saúde e sobrecarrega o sistema de justiça.

Outro artigo (26) citou a iniciativa de uma magistrada de Araguaína (TO) que, em 2011, estabeleceu convênio com a Prefeitura, a Ouvidoria e a Secretaria de Saúde, juntamente com o NAT, tendo conseguido que $72 \%$ das demandas em saúde fossem solucionadas e somente $28 \%$ dos processos seguissem pela via judicial.

As autoras (26) defenderam que a polissemia e a complexidade técnico-científica das questões afetas à saúde; a dimensão dos interesses variados envolvidos no cenário da judicialização (médicos, laboratórios farmacêuticos, associações de pacientes, escritórios de advocacia); e o peso decisório sobre os magistrados são tamanhos que não haveria outra modelagem possível para a superação das lides em saúde senão pelo diálogo institucional. Destacam que as Jornadas de Direito à saúde do CNJ surgem como espaços de direito interinstitucional profícuos. 
Um dos artigos (24) apurou, com base em um questionário aplicado a 30 procuradores do MP vinculados à Comissão Permanente de Defesa da Saúde (COPEDS) e/ou Associação Nacional do Ministério Público de Defesa da Saúde (AMPASA), que a maioria valoriza as ferramentas extrajudiciais (como Termos de Ajustamento de Conduta (TACs); inquérito civil; telefonemas para gestores da saúde;, reuniões com gestores da saúde;, participação nas reuniões dos conselhos e conferências de saúde) na tratativa das questões de saúde, sendo que todos eles entendem que a atuação extrajudicial do MP na temática da saúde mitiga efetivamente a judicialização da saúde.

Os autores destacaram que a iniciativa de criação desses dois mecanismos institucionais de diálogo intersetorial (COPEDS e AMPASA) já elevam o MP a uma posição vanguardista na tutela do direito coletivo à saúde e no manejo da judicialização da saúde.

Essa última premissa foi mais bem detalhada por autor coincidente em outro estudo, também componente da amostra selecionada (20), no qual defendeu que a discussão das questões da saúde pode ser realizada sob ponto de vista jurídico e resolutivo, sem que necessariamente se faça uso de ação judicial, ao que o autor denomina juridicizar ao invés de judicializar.

O autor (20) compreendeu ser o MP o ator institucional com melhores condições de assumir um papel mediador nos conflitos ligados ao direito à saúde: pela sua propriedade de atuar em proteção a direitos de titularidade coletiva, como a saúde, sem necessidade de provocação; ao dispor de ferramentas extrajudiciais para manejo de conflitos; e por sua inserção neutra em relação aos poderes Judiciário e Executivo, que compõem a interface institucional por trás da judicialização da saúde. O autor entendeu que o debate da judicialização da saúde não pode estar centrado na figura do juiz, pois isso privilegiaria o referencial judicial e o próprio Poder Judiciário sobre uma seara que é claramente interdisciplinar.

Outro artigo (22) destacou, como iniciativa de diálogo intersetorial, a publicação da Recomendação CNJ n 43/2013 (23), que incentiva os Tribunais de Justiça e os Tribunais Regionais Federais a fomentar a especialização de varas para lidar com ações afetas ao direito à saúde. Apesar desse avanço, os autores foram enfáticos na compreensão de que é necessário renunciar à tendência de superveniência do direito sobre a saúde no debate propositivo da judicialização da saúde pela via da apropriação dos conteúdos sanitários pelo direito por meio de consultorias técnicas, audiências públicas e celebração de convênios de 
cooperação técnica intersetorial que abranjam tribunais, órgãos gestores da saúde e instituições de pesquisa.

\section{Discussão}

Ganha destaque o fato deste estudo trazer um olhar pioneiro ao tema: não foram localizadas RSLs que analisassem o estado da arte das iniciativas de diálogo institucional intersetorial no escopo da judicialização da saúde no Brasil, em que pese a gravidade do cenário factual.

Todos os artigos selecionados citaram iniciativas de articulação institucional que constam das recomendações feitas pelo CNJ, MS e Anvisa. O diálogo institucional intersetorial, entretanto, não é conquista que se concretize na mera publicação de disposições a seu favor. Entre matrizes de saberes tão distintas e fundamentos epistemológicos tão opostos como os que se demonstram no binômio saúde-direito, podese figurar a existência de abismos interpretativos que dificultam a compreensão do lugar de alteridade das instituições, seus atores e sua missão. (27).

Todos os autores concordaram com a densidade e complexidade das questões que cercam o fenômeno da judicialização da saúde, o que impõe a necessidade de enfrentamento interdisciplinar do problema.

Dois artigos concordam com a percepção de que se reúnem no MP as condições formais mais favoráveis para atuar como disparador de iniciativas de diálogo intersetoriais por meio de ferramentas extrajudiciais e para atuar como mediador nas ações judiciais afetas à saúde $(20,24)$. Entretanto, embora reconheçam o valor das articulações em curso, outros autores (23) entenderam que o diálogo intersetorial deveria ser conduzido pelos atores da saúde e ser incorporado aos espaços institucionais do sistema de saúde (secretarias estaduais e municipais), o que privilegiaria a lógica técnico-científica do debate e romperia com o preterimento por qual passam os argumentos sanitários quando a temática é conduzida por atores do direito em espaços institucionais do sistema jurídico.

Tais estratégias não se antagonizam frontalmente. Trata-se apenas da coexistência de caminhos possíveis em busca da superação de uma dimensão tensional entre os sistemas e que permita uma atuação colaborativa e dialógica $(4,8)$.

Outros dois artigos ressaltaram a oposição existente entre a lógica adversarial de operar o Direito - aprendida desde o útero acadêmico e reforçada na prática competitiva tão característica desse nicho profissional - e a proposta dialógica colaborativa e articulada que 
se apresenta como única alternativa à expansão da judicialização da saúde $(21,22)$. Essa vertente sugeriu que parte importante da prevenção dos excessos da judicialização da saúde reside na formação dos futuros operadores de Direito.

Houve estudos que destacaram iniciativas de articulação, iniciadas por um ator de relevância isolado (em ambos os casos, juízes), e que culminaram com modelagens consolidadas e incorporadas institucionalmente aos sistemas de direito e de saúde local e regional $(25,26)$.

Tal fato reforça a dependência que a abertura de uma primeira articulação intersetorial guarda com a existência de perfis profissionais marcados por comprometimento, capacidade de agregação, disposição para troca de conhecimentos e inquietação com os desdobramentos desfavoráveis da judicialização da saúde para a macrojustiça e para a garantia do direito coletivo à saúde $(28,29)$.

Depreende-se o surgimento de diversas frentes de atuação articulada intersetorial, algumas já em fase de apropriação institucional e em vias de consolidação ao status de política pública (judiciária e de saúde), outras em momento embrionário a partir do que vislumbram os estudiosos do tema.

A articulação que se apresenta entre os sistemas parece não possuir ressalvas, não tendo sido mencionado pelos artigos nenhum aspecto negativo entre seus desdobramentos. Entre as vantagens, os autores apontam ganhos de maturidade institucional intersetorial; compartilhamento de saberes técnico-científicos; agilidade na fruição do direito à saúde e no acesso à justiça; melhoria do sistema de saúde no âmbito local e macro; redução das ações judiciais em saúde; e mitigação do fenômeno da judicialização da saúde.

É possível considerar que o diálogo institucional intersetorial é uma modelagem de caráter livre; possível de ser desenhado sob os moldes das peculiaridades locais; por iniciativa inicial de operadores do direito ou gestores da saúde ou de forma conjunta; e com forte evidência preditiva de êxito e ganhos institucionais e sociais aos sistemas de saúde e judicial.

\section{Considerações finais}

Por meio do relato dos autores dos sete artigos selecionados neste estudo foi possível identificar iniciativas de diálogo institucional intersetorial no escopo da judicialização da saúde, implementadas desde a recomendação formal para o avanço nessa direção pelo Fórum da Saúde do CNJ em 2010. Residualmente, também foram elencadas percepções 


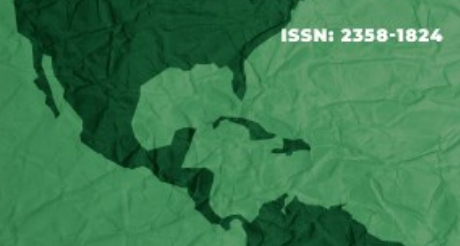

que sinalizam dificuldades e oportunidades que se apresentam no desafio dialógico entre saúde e direito para manejo do fenômeno da judicialização da saúde.

\section{Referências}

1. Brasil. Constituição (1988). Constituição da República Federativa do Brasil [Internet]. Brasília, DF: Senado Federal; 2016 [citado em 19 Mar 2019]. 496 p. Disponível em: https://www.senado.leg.br/atividade/const/con1988/con1988_08.09.2016/CON1988.pdf

2. Tate $\mathrm{N}$, Vallinder T. The global expansion of judicial power. New York: New York University Press; 1995.

3. Pepe VLE, Figueiredo TA, Simas L, Osorio-de-Castro CGS, Ventura M. A judicialização da saúde e os novos desafios da gestão da assistência farmacêutica. Ciênc. saúde coletiva [Internet]. 2010 [citado em 30 mar. 2019];15(5): 2405-2414. Disponível em: http://www.scielo.br/scielo.php?script=sci_arttext\&pid=S1413-81232010000500015\&Ing=en doi https://doi.org/10.1590/S1413-81232010000500015

4. Catanheide ID, Lisboa ES, Souza LEPF. Características da judicialização do acesso a medicamentos no Brasil: uma revisão sistemática. Physis [Internet]. 2016 [citado em 2 fev. 2019];26(4): 1335-1356. Disponível em:

http://www.scielo.br/scielo.php?script=sci_arttext\&pid=S0103-73312016000401335\&lng=en doi https://doi.org/10.1590/s0103-73312016000400014

5. Vieira FS, Zucchi P. Distorções causadas pelas ações judiciais à política de medicamentos no Brasil. Rev. Saúde Pública [Internet]. 2007 [citado em 5 fev. 2019]; 41(2): 214-222. Disponível em: http://www.scielo.br/scielo.php?script=sci_arttext\&pid=S0034$89102007000200007 \&$ Ing=en doi https://doi.org/10.1590/S0034-89102007000200007

6. Wang DWL, Vasconcelos NP, Oliveira VE, Terrazas FV. Os impactos da judicialização da saúde no município de São Paulo: gasto público e organização federativa. Rev. Adm. Pública [Internet]. 2014 [citado em 3 fev. 2019];48(5): 1191-1206. Disponível em: https://www.scielo.br/scielo.php?script=sci_arttext\&pid=S003476122014000500006\&lng=en\&nrm=iso\&tlng=pt doi https://doi.org/10.1590/0034-76121666

7. Ramos K, Ferreira ASD. Análise da demanda de medicamentos para uso off label por meio de ações judiciais na Secretaria de Estado de Saúde de Minas Gerais. Rev. Dir. Sanit. [Internet]. 2013 [citado em 10 fev. 2019];14(1):98-121. Disponível em: https://www.revistas.usp.br/rdisan/article/view/56626 doi https://doi.org/10.11606/issn.23169044.v14i1p98-121

8. Anjos ECS. Judicialização da saúde no Brasil: uma revisão sistemática da literatura sobre o acesso a ações e serviços de saúde. [Dissertação na Internet]. Rio de Janeiro: Escola Nacional de Saúde Pública Sérgio Arouca, Fundação Oswaldo Cruz; 2019 [citado em 2 set. 2019]. Disponível em: https://www.arca.fiocruz.br/handle/icict/40222

9. Zebulum JC. Os conflitos morais enfrentados pelos juízes em demandas de saúde: o 


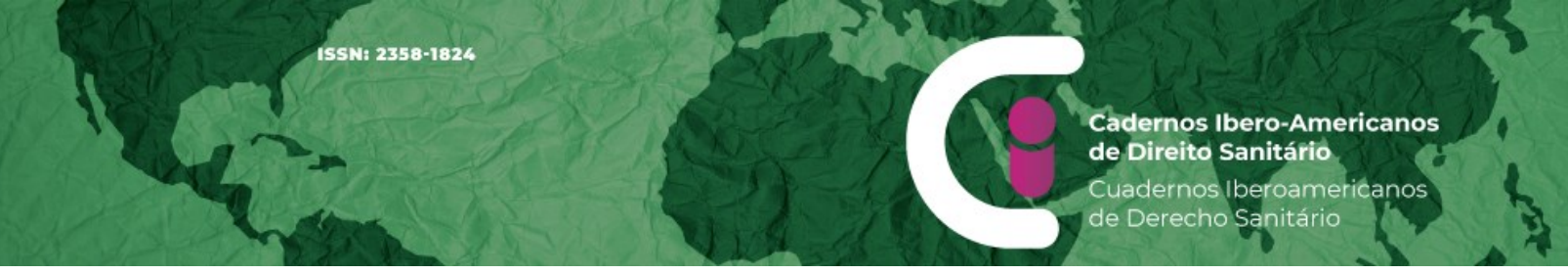

caso dos tribunais federais brasileiros. Rev. Dir. Sanit. [Internet]. 2018 [citado em 10 fev. 2019]; 19(1):144-65. Disponível em: https://www.revistas.usp.br/rdisan/article/view/148132 doi https://doi.org/10.11606/issn.2316-9044.v19i1p144-165

10. Pimenta KKP, Gonçalves Júnior O. Judicialização da saúde pública no Brasil: padrões e divergências decisórias na Justiça Civil Comum do Estado de São Paulo, Comarca de Campinas. RJD [Internet]. 2017 [citado em 13 fev. 2019];31(2):386-08. Disponível em: http://seer.upf.br/index.php/rjd/article/view/6845 doi https://doi.org/10.5335/rjd.v31i2.6845

11. Romero LCP. A jurisprudência do Tribunal de Justiça do Distrito Federal em ações de medicamentos. Rev. Dir. Sanit. [Internet]. 2010 [citado em 3 abr. 2019]; 11(2):11-59. Disponível em: https://www.revistas.usp.br/rdisan/article/view/13207. https://doi.org/10.11606/issn.2316-9044.v11i2p11-59.

12. Machado FRS, Dain S. A Audiência Pública da Saúde: questões para a judicialização e para a gestão de saúde no Brasil. Rev. Adm. Pub. [Internet]. 2012 [citado em 19 mar. 2019];46(4):1017-1036. Disponível em: https://www.scielo.br/scielo.php?pid=S003476122012000400006\&script=sci_abstract\&tIng=pt doi https://doi.org/10.1590/S003476122012000400006

13. Valle GHM, Camargo JMP. A audiência pública sobre a judicialização da saúde e seus reflexos na jurisprudência do Supremo Tribunal Federal. Rev. Dir. Sanit. [Internet]. 2011 [citado em 16 mar. 2019];11(3):13-31. Disponível em:

https://www.revistas.usp.br/rdisan/article/view/13220 doi https://doi.org/10.11606/issn.23169044.v11i3p13-31

14. Santos AO, Marques SB. A abordagem de aspectos jurídicos na Audiência Pública da saúde no Supremo Tribunal Federal. Cad. Ibero Am. Direito Sanit. [Internet]. 2014 [citado em 22 mar. 2019];3(3):1-24. Disponível em:

https://www.cadernos.prodisa.fiocruz.br/index.php/cadernos/article/view/50 doi https://doi.org/10.17566/ciads.v3i3.50.

15. Brasil. Conselho Nacional de Justiça (CNJ). Recomendação $n^{\circ} 31$, de 30 de março de 2010. Recomenda aos Tribunais a adoção de medidas, visando melhor subsidiar os magistrados e demais operadores do direito, para assegurar maior eficiência na solução das demandas judiciais envolvendo a assistência à saúde. Brasília, 2010. Diário da Justiça Eletrônico n 61/2010, p. 4-6, 7 abr. 2010.

16. Brasil. Conselho Nacional de Justiça (CNJ). Resolução $n^{\circ}$ 107, de 6 de abril de 2010. Institui o Fórum Nacional do Judiciário para monitoramento e resolução das demandas de assistência à saúde. Brasília, 2010. Diário da Justiça Eletrônico n 61/2010, p. 9-10, 7 abr. 2010.

17. Conselho Nacional de Justiça (CNJ). Fórum da Saúde [Internet]. [citado em 02 mar. 2019]. Disponível em: https://www.cnj.jus.br/programas-e-acoes/forum-da-saude-3/

18. Meerpohl JJ, Herrle F, Reinders S, Antes G, von Elm E. Scientific Value of Systematic Reviews: Survey of Editors of Core Clinical Journals. PLoS ONE [Internet]. 2012 [cited jn 12 Jan 2019];7(10): e35732,1-5. Available from: 


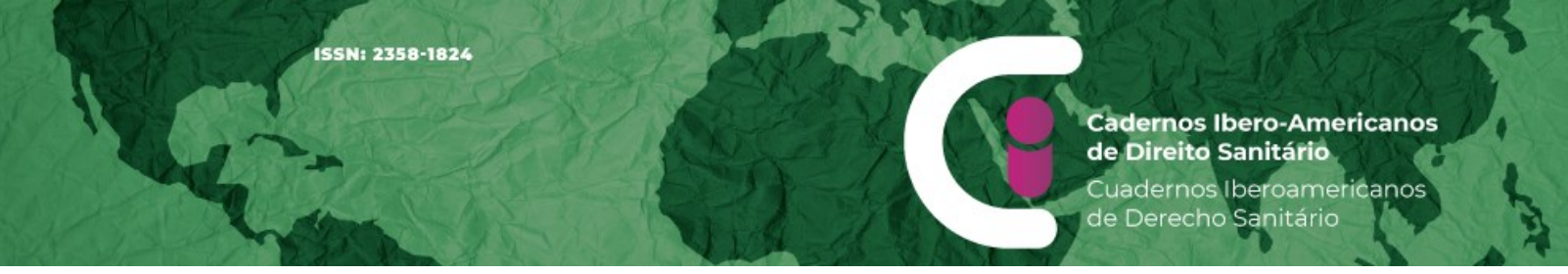

https://journals.plos.org/plosone/article?id=10.1371/journal.pone.0035732 doi https://doi.org/10.1371/annotation/b9a9cb87-3d96-47e4-a073-a7e97a19f47c

19. Galvão TF, Pansani TSA, Harrad D. Principais itens para relatar revisões sistemáticas e meta-análises: A recomendação PRISMA.-Epidemiol. Serv. Saúde [Internet]. 2015 [citado 4 jan. 2019]];24(2):335-342. Disponível em:

http://scielo.iec.gov.br/scielo.php?script=sci_arttext\&pid=S1679-

49742015000200017\&lng=pt doi https://dx. $\mathbf{d o i}$. org/10.5123/S1679-49742015000200017

20. Asensi FD. Judicialização ou juridicização? As instituições jurídicas e suas estratégias na saúde. Physis [Internet]. 2010 [citado em 11 mar. 2019];20(1): 33-55. Disponível em: http://www.scielo.br/scielo.php?script=sci_arttext\&pid=S0103-73312010000100004\&lng=en doi https://dx.doi.org/10.1590/S0103-7331̄2010000100004.

21. Gomes DF, Souza CR, Silva FL, Pôrto JA, Morais IA, Ramos MC, Silva EN. Judicialização da saúde e a audiência pública convocada pelo Supremo Tribunal Federal em 2009: o que mudou de lá para cá? Saúde debate [Internet]. [citado em 10 mar. 2019]; 38(100):139-156. Disponível em:

http://www.scielo.br/scielo.php?script=sci_arttext\&pid=S0103-

$11042014000100139 \&$ Ing=en doi https://dx.doi.org/10.5935/0103-104.20140008.

22. Matta JLJ, Marques GL. A prestação jurisdicional excessiva como risco ao princípio da universalidade do SUS: pela naturalização do diálogo entre o Direito e a Saúde. Revista Jurídica da Presidência [Internet]. 2014 [citado em 8 mar 2019];16(109):421-441.

Disponível em: https://revistajuridica.presidencia.gov.br/index.php/saj/article/view/18. doi https://dx.doi.org/10.20499/2236-3645.RJP2014v16e109-18

23. Delduque $M C$, Castro EV. A Mediação Sanitária como alternativa viável à judicialização das políticas de saúde no Brasil. Saúde debate [Internet]. 2015 [citado em 01 mar. 2021];39(105):506-513. Disponível em:

http://www.scielo.br/scielo.php?script=sci_arttext\&pid=S0103-

11042015000200506\&lng=en. doi https://dx.doi.org/10.1590/0103-110420151050002017

24. Asensi FD, Aidar A, Dias D, Ferreira A, Barcelos J, Sallum R et al. O judicial e o extrajudicial: Ministério Público e direito à saúde no Brasil. Revista de Direito Administrativo \& Constitucional [Internet]. 2015 [citado em 10 mar. 2019]:1(6):179-205. Disponível em: http://www.revistaaec.com/index.php/revistaaec/article/view/57 doi https://dx.doi.org/10.21056/aec.v15i60.57

25. Asensi FD, Pinheiro R. Judicialização da saúde e Diálogo Institucional: A experiência de Lages (SC). Rev. Dir. Sanit. [Internet]. 2016 [citado em 2 abr. 2019];17(2):48-65. Disponível em: http://www.revistas.usp.br/rdisan/ article/view/122306/119043 doi https://dx.doi.org/10.11606/issn.2316-9044.v17i2p48-65

26. Avila APO, Melo KCC. Separação de poderes e diálogos institucionais nos litígios envolvendo o direito à saúde. Rev. Invest. Const. [Internet]. 2018 [citado em 3 abr. 2019];5(1):83-108. Disponível em: https://www.scielo.br/scielo.php?script=sci_arttext\&pid=S2359-56392018000100083 doi https://dx.doi.org/10.5380/rinc.v5i1.54934 
27. Irigaray HAR, Cunha GX, Harten BA. Missão organizacional: o que a análise crítica do discurso revela? Cad. EBAPE.BR [Internet]. 2016 [citado em 5 mar. 2019];14 (4):920-933. Disponível em: https://www.scielo.br/scielo.php?pid=S167939512016000400920\&script=sci_abstract\&tIng=pt doi https://dx.doi.org/10.1590/1679395133162

28. Kirschbaum C, Iwai T. Teoria dos jogos e microssociologia: avenidas de colaboração. Rev. Adm. Contemp. [Internet]. 2011 [citado em 2 fev. 2019];15(1):138-157. Disponível em: http://www.scielo.br/scielo.php?script=sci_arttext\&pid=S1415-65552011000100009\&Ing $=e$ n\&nrm=iso. Doi https://dx.doi.org/10.1590/S1415-65552011000100009

29. Leoneti AB, Oliveira SVWB, Oliveira MMB. O equilíbrio de Nash como uma solução para o conflito entre eficiência e custo na escolha de sistemas de tratamento de esgoto sanitário com o auxílio de um modelo de tomada de decisão. Eng. Sanit. Ambient. [Internet]. 2010 [citado em 9 fev. 2019];15(1):53-64. Disponível em: http://www.scielo.br/scielo.php? script=sci_arttext\&pid=S141341522010000100007\&lng=en\&nrm=isso doi https://doi.org/10.1590/S141341522010000100007

\section{Colaboradores}

Anjos ECS contribuiu com a concepção; análise e interpretação de dados; redação; revisão crítica; e aprovação da versão final do artigo. Ribeiro DC e Morais LV contribuíram com a concepção, análise dos dados e resultados do artigo.

\section{Como citar este artigo}

Anjos ECS, Ribeiro DC, Morais LV. Judicialização da saúde: uma revisão sistemática de literatura das iniciativas de diálogo institucional intersetorial. Cadernos Ibero-Americanos de Direito Sanitário. 2021 jan./mar.;10(1):113-128. 